\title{
THE SPECIAL POSITION OF THE RED CROSS
}

Mr. A. van Emden, Director-General of the Netherlands Red Cross, has produced an interesting article concerning the special position which the Red Cross occupies amongst other humanitarian institutions. This article has appeared in Panorama, the Review of the League of Red Cross Societies and also in the Netherlands Red Cross Review and which we think will be of interest.

The Red Cross prevents and alleviates human suffering in time of war as in time of peace, irrespective of class, race, nationality, religion, political beliefs or any other criterion, solely on the basis of humanitarian principles. This line of conduct has been and still is being followed daily in many different situations, for despite outstanding progress in different spheres and all that has been achieved by modern techniques and growing civilization, present-day society still desperately needs help in relieving human suffering.

The Red Cross constantly provides such aid, sometimes discreetly, sometimes in a more spectacular way, but always in accordance with the basic principles governing Red Cross work.

As a result most countries recognize and appreciate the position of our organization. This is undoubtedly the case where the Red Cross has gradually become a part of everyday life and has had time to organize its activities. However, in some cases, especially in countries where public health and social services have reached a certain level, the Red Cross is looked upon simply as one of a number of organizations engaged in such work. Here it should be emphasized that the Red Cross acknowledges and admires the achievements of other bodies and in no way considers itself superior. Nevertheless its position is special and even unique, and the following points deserve underlining :

Its impartiality.-Many organizations working in public health, social welfare or other fields, owe their origin to the initiative of 


\section{IN THE RED CROSS WORLD}

specific groups and may in the course of their work exercise a certain discrimination as regards, for example, religion or philosophical ideas. The Red Cross, by its very principles, is precluded from any type of harmful restriction towards those needing relief.

Its flexibility.-In nearly every country the Red Cross carries out quite a wide range of activities, but takes care, and we believe rightly so, not to encroach in areas where one or several other social organizations are already at work. Just as clearly, of course, the Red Cross by its nature cannot refuse any task falling within its competence, as this would be prejudicial to those who had turned to it for special assistance.

Its international strength.-The Red Cross Societies throughout the world are united in an international organization. This constitutes a link between the National Societies, which often, in the event of major disasters for example, give each other valuable assistance. In addition it enables the exchange of experience to everyone's benefit, either directly or through its publications, and is also designed to stimulate and co-ordinate.

Its duties under the Geneva Conventions.--The four Geneva Conventions confer very specific duties on the Red Cross in time of war or threat of war. For these to be satisfactorily performed, it is obviously necessary to make preparations in peacetime particularly by the purchase and maintenance of equipment, the training of personnel and negotiations with the Army medical service.

Its volunteer workers. - The Red Cross relies, often much more than other organizations, on a large number of volunteer workers. The volunteer system strengthens the bonds between personnel and the Red Cross and helps enlist public sympathy. This is important because the Red Cross must frequently appeal to the generosity of the public if it is to do its work well and continue to develop.

Its appeal to youth.-The Red Cross incorporates young people in its activities by assigning specific tasks to the Junior Red Cross, for instance training for the promotion of health, friendship and 
service. Some countries have a junior organization with individual members ; in others there is simply a programme in which clubs or schools co-operate. In both cases the main purpose is to familiarize young people with the work and ideals of the Red Cross and give them the opportunity to participate in certain activities. A closer knowledge of the Red Cross and its principles will lead many of them to join their seniors when they grow up and eventually take over the work.

The special position of the Red Cross among other humanitarian organizations is clearly recognized in some countries but less so in others. It is important for us that each National Red Cross Society should endeavour to consolidate this position in the whole social organization of its country. Exchange of experience in this respect can be a useful contribution to international contacts.

This special position of the Red Cross raises the question whether after all it can establish close relations-and even collaboratewith other bodies whose aim is also the alleviation of human suffering. We would answer : yes. Both contact and collaboration are desirable and valuable. But the Red Cross can never forget that it must preserve its neutral attitude, an imperative which is not always fully understood by others and is even sometimes regarded as an unwillingness to collaborate.

This situation, though regrettable in itself, in reality confirms the special position of the Red Cross. I hope that this brief review of that position, particularly in relation to other organizations with humanitarian aims, may help to reduce and even eliminate some of the misunderstandings which exist. The whole sector of humanitarian assistance stands to gain. 